\title{
A Capstone and Design Project on Process Automation: Technical Details and Student Learning
}

\section{Mr. Michael Ghossein}

My name is Michael Ghossein I have a Bachelors Degree in Control and Instrumentation Engineering Technology from the University of Houston - Downtown. I currently work at Shell Deer Park as a Process Operator (5 years experience). I intend to use my education to start a career in Controls and Instrumentation.

\section{Linda M. DeLosSantos, University of Houston, Downtown Dr. Vassilios Tzouanas, University of Houston, Downtown}

Vassilios Tzouanas is an Associate Professor of Computer Science and Engineering Technology at the University of Houston - Downtown, in Houston, Texas. He also serves as assistant department chairman. He received all his degrees in chemical engineering and obtained his Ph.D. from Lehigh University. He has worked in the industry for 19 years where he held technical and management positions with major operating companies as well as process control technology development companies. Since 2010, he has been with UHD where he teaches university courses in process control, modeling and simulation, process design and operation, applied thermodynamics and heat transfer, and numerical methods. Dr. Tzouanas research interests include process modeling, simulation and design, process control, and renewable energy systems. Dr. Tzouanas is an ABET Program Evaluator (PEV) for Engineering and Engineering Technology programs. He is also member of AIChE and ASEE.

\section{Omar Meraz}

I am a retired U.S. Army Sergeant, who recently graduated from the University of Houston-Downtown, with a degree in CIET. I enjoy spending my free time with my two daughters who are eight and two. 


\title{
A Capstone and Design Project on Process Automation: Technical Details and Student Learnings
}

\begin{abstract}
This paper refers to a capstone and design project and discusses the design, construction, instrumentation, modeling, simulation and control of a binary distillation column. In addition to technical details, student learnings on project management, teamwork, and technical communication are also presented. Results demonstrate the aptitude and skills of engineering technology students to use sophisticated technologies to solve important technical problems while working in a team environment and delivering results within budget and schedule constraints.
\end{abstract}

\section{Introduction}

Manufacturing industries operate under various constraints while trying to be competitive in today's business environment. For instance, they must operate safely and in an environmentally friendly manner with minimum carbon footprint. This requires better utilization of raw materials and less energy consumption. One of the most energy consuming manufacturing processes is the distillation process. Improved distillation column design and automated operation are very important in achieving energy reduction for such processes. Thus, graduates from engineering/engineering technology programs must be taught and master the required technologies and develop skills to implement design and automation projects in a team-based environment with schedule and budget constraints.

The Engineering Technology (ET) program at the University of Houston-Downtown includes a number of courses on process control, process modeling and simulation, electrical/electronic systems, instrumentation, computer technologies, and communication systems. To meet graduation requirements for the degree of Bachelor of Science in Engineering Technology, students must work in teams and complete a capstone and design project. This project, also called senior project in our terminology, provides students with an opportunity to work on complex control problems, similar to ones encountered in industry, and employ a number of technologies and methods to provide a practical solution.

In general, the senior project entails the design and construction of a process, identification of key control objectives, specification and installation of required instrumentation for process variable(s) monitoring and control, real time data acquisition, process modeling using empirical and/or analytical methods, design and tuning of controllers, and closed loop control performance evaluation. Since the senior project is a team-based project, equally important to technical requirements are a number of non-technical requirements focusing on project management, technical writing and presentation of technical topics, teamwork and communication.

This paper discusses the design, construction, instrumentation, modeling, simulation, and control of a binary distillation column. In addition to technical details, student learnings on project management, budget and schedule development, teamwork, and technical communication are also presented. The remaining of the paper is organized as follows. Section 2 discusses the process and control objectives. Section 3 provides details on the column design using AspenPlus. Sections 4 refers to the computer platform, for data acquisition and operation of the process. Section 5 presents experimental results. Section 6 summarizes student experiences and lessons learned while 
working on this capstone and design project. Section 7 summarizes main results and is followed by references.

\section{The Process and Control Objectives}

A schematic diagram of the distillation process is shown in Figure 1. The column has 7 trays. Feed enters on tray 2. The column was designed for the separation of a binary mixture of water and propylene glycol. However, following column construction, its performance was tested by separating a mixture of ethanol and water for two reasons: firstly, this feedstock was available as the fermentation product of the lab's bioreactor; secondly, the university's HSE department expressed concerns due to the higher temperature required for the water/propylene glycol separation.

The column operates in continuous, closed loop mode. Feed is separated into two products which are eventually pumped into the feed drum for reprocessing in a continuous manner. Reflux drum and bottoms/reboiler levels are maintained by adjusting the distillate and bottoms product flow rates. A heating element is used to supply the energy required for the separation. The reboiler vapor stream temperature is maintained by adjusting the supplied heat. Reflux is manually adjusted. Overhead vapor is condensed by using cooling water from a lab water supply.

The control objectives are to maintain material inventory by controlling the reflux drum and bottoms/reboiler levels by manipulating the speed of the pumps on the distillate and bottoms product lines, respectively. Separation is maintained by controlling the reboiler temperature using the heat supplied to the column. Thus, three controllers are designed to operate in automatic mode to achieve these control objectives. Feed flow-rate and reflux flow-rate are adjusted using two controllers which are currently operated in manual mode. The feedback control loop diagrams are shown in Figures 2 through 4.

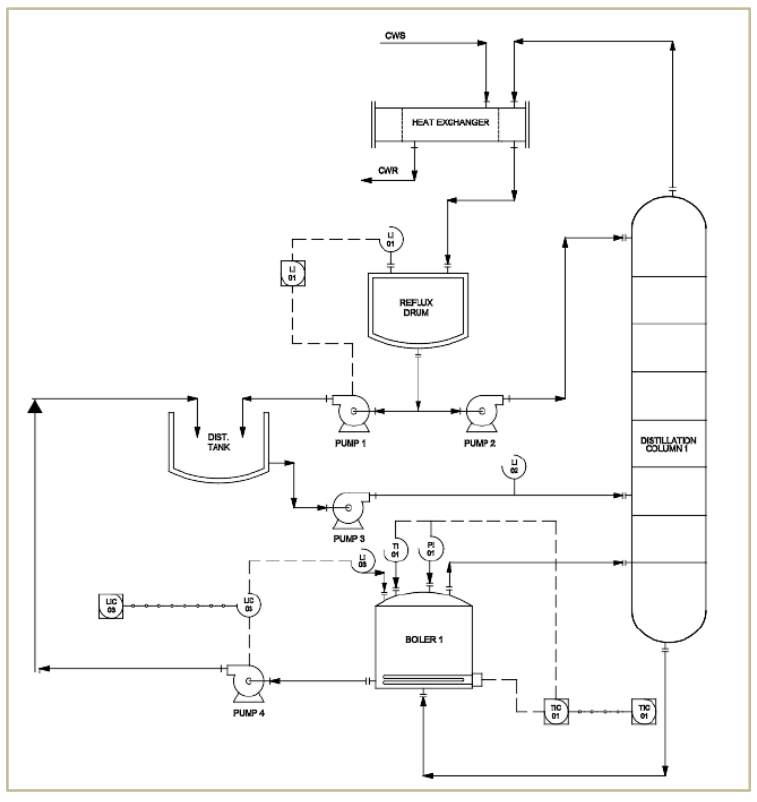

Fig. 1: Schematic of the Distillation Column 


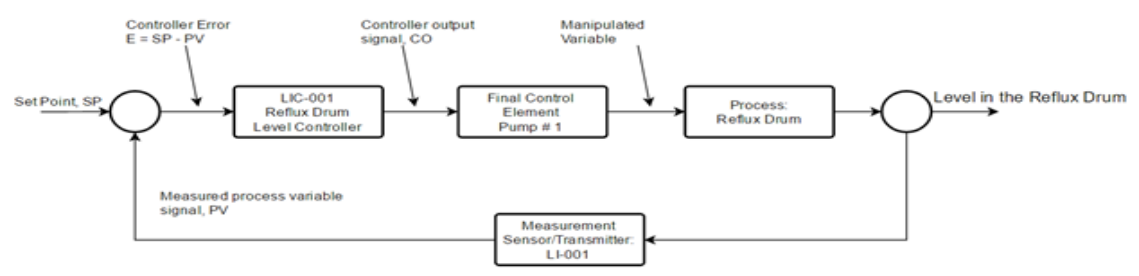

Fig. 2: Reflux Drum Level Control Loop

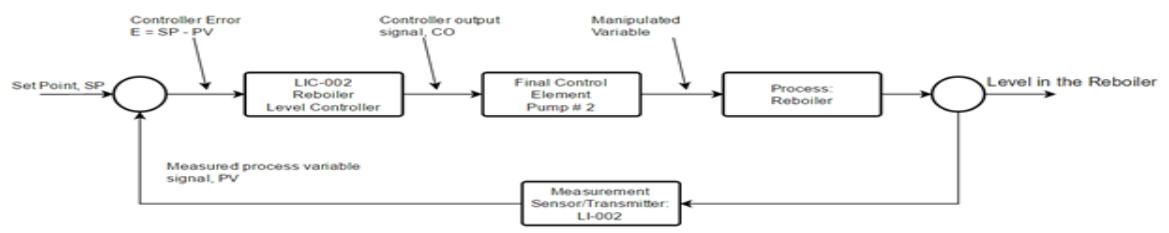

Fig. 3: Reboiler Level Control Loop

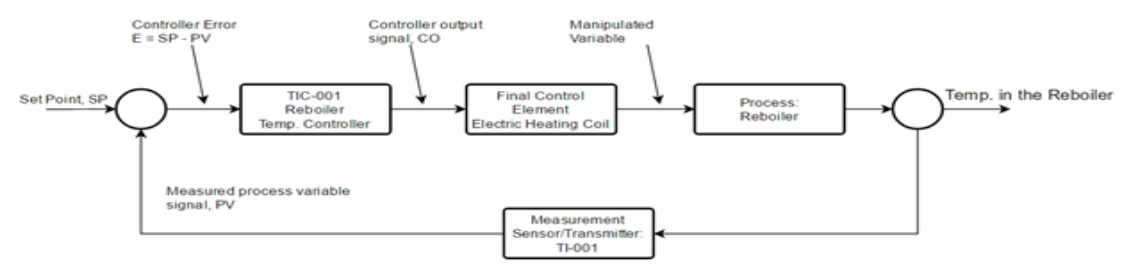

Fig. 4: Reboiler Temperature Control Loop

\section{Distillation Column Design using AspenPlus}

As mentioned previously, the column was initially designed for the water/propylene glycol mixture but was tested using the ethanol/water mixture. So, this section shows design results for the water/propylene glycol mixture using AspenPlus ${ }^{1}$. Design data is given in Table A.1 in Appendix A.

Figure 5 shows the process flowsheet in AspenPlus. Block DSTW is used to design the column.

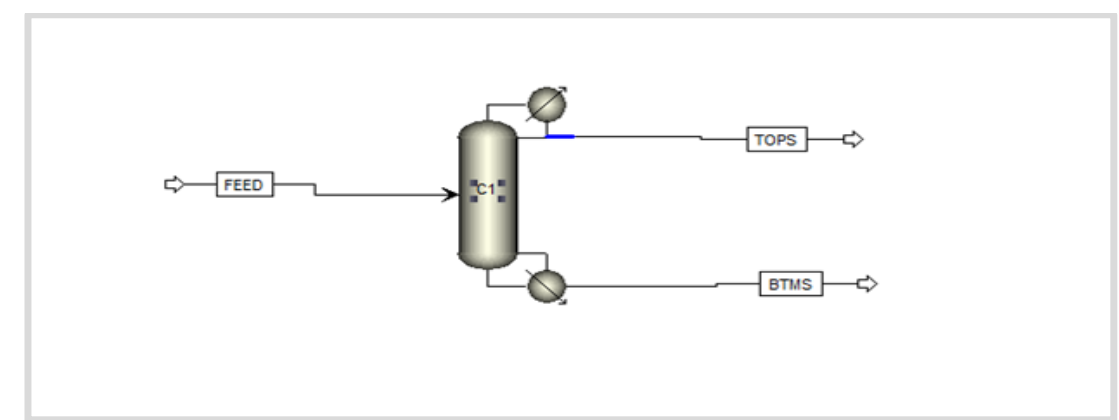

Fig. 5: AspenPlus Column Schematic

Feed stream specifications are shown in Figure 6. It is assumed that the feed temperature is around $66^{\circ} \mathrm{C}$ at $1 \mathrm{~atm}$ (because of the continuous loop back to the feed drum). 


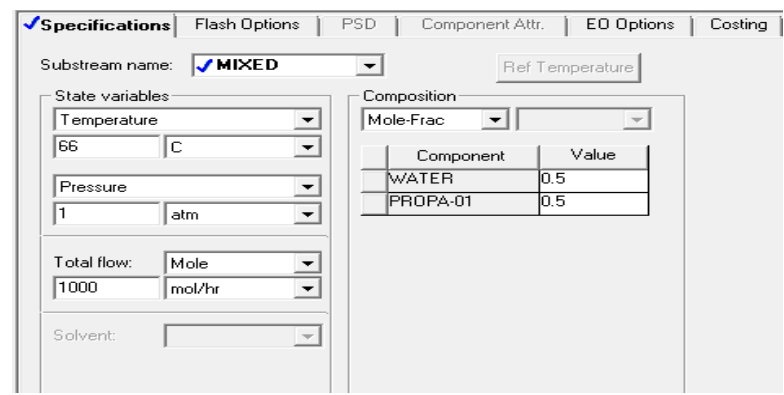

Fig. 6: Feed Specifications Setup

In Figure 7, other design parameters are specified. The reflux ratio is 0.5 . The component recoveries were set to $98 \%$ for water and $2 \%$ for propylene glycol in the distillate product. The pressures in the condenser and reboiler are set to $1 \mathrm{~atm}$. A total condenser is used.

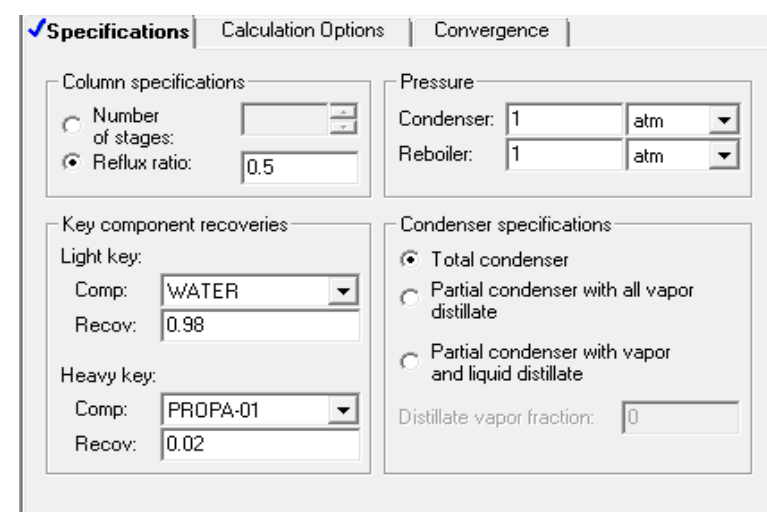

Fig. 7: Column Specification Setup

Figure 8 below indicates that the number of actual trays, NT, is 5 (4.38 is rounded up). Notice that in AspenPlus terminology, the condenser and reboiler are counted as trays and numbering of trays starts with the condenser as tray number 1. So, actually, inside the column there should be 3 trays. The feed tray location is on tray 2 (counting from the bottom of the column). These results are in agreement with the McCabe-Thiele method (see Appendix A).

\begin{tabular}{|c|c|c|c|}
\hline \multicolumn{4}{|c|}{ Minimum reflux ratio: } \\
\hline & Actual reflux ratio: & 0.5 & \\
\hline & Minimum number of stages: & 2.53311503 & \\
\hline & Number of actual stages: & 4.38289382 & \\
\hline & Feed stage: & 3.44233344 & \\
\hline & Number of actual stages above feed: & 2.44233344 & \\
\hline & Reboiler heating required: & 46161.2989 & Btu/hr \\
\hline & Condenser cooling required: & 31210.9899 & Btu/hr \\
\hline & Distillate temperature: & 214.06545 & $\mathrm{~F}$ \\
\hline & Bottom temperature: & 343.419882 & $\mathrm{~F}$ \\
\hline & Distillate to feed fraction: & 0.5 & \\
\hline & HETP: & & \\
\hline
\end{tabular}

Fig. 8: AspenPlus Column Design Results

To account for future projects, it was decided to design the column with 7 bubble cup trays instead of the required 3 trays (excluding reboiler and condenser). The as built distillation column is shown in Figure 9. 


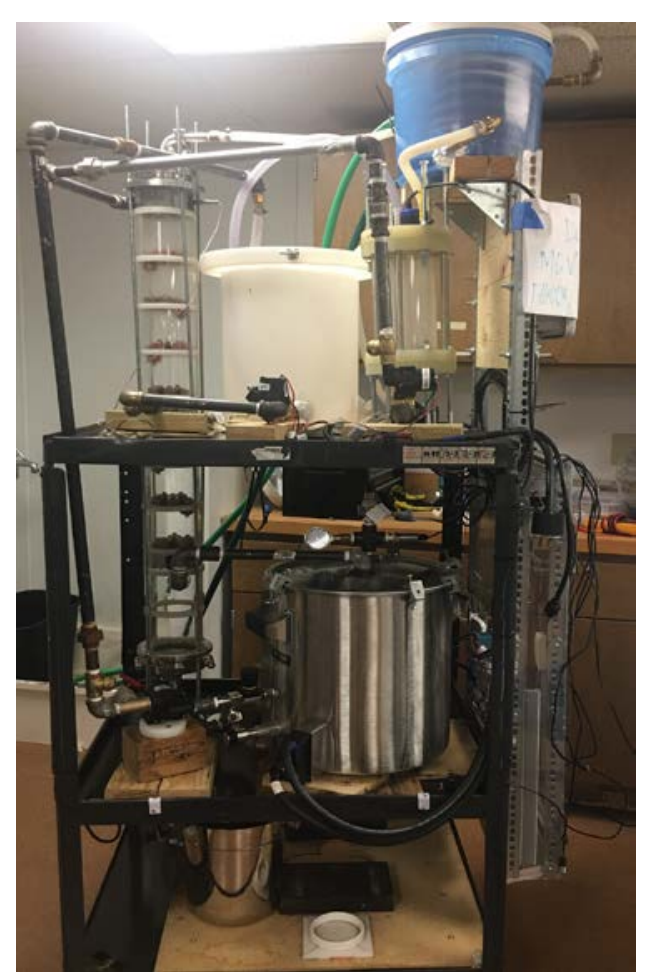

Fig. 9: The as built Distillation Column

Major parts used to build the column along with specifications and sources are included in Appendix B.

\section{The Control Platform}

\section{Human Machine Interface (HMI) and LabVIEW Programming}

Aside from constructing the distillation column, three proportional-integral-derivative (PID) controllers were implemented to achieve the following control objectives: reflux drum level control; reboiler level control; reboiler temperature control with a high pressure low select override. LabVIEW with myRIO by National Instruments ${ }^{2}$ is used for data acquisition and control. LabVIEW is used widely for research purposes while myRIO allows for several input/output variables which is the case for monitoring and controlling the operation of the distillation column. Because of the particular type of electric signals used by myRIO, conversion from current to voltage and proper scaling is needed in several cases.

Figure 10 below shows the front panel of the LabVIEW program which is used as HumanMachine-Interface (HMI) to operate and control the column. It is divided into four squares to provide a user-friendly control of the distillation column. The bottom two squares are used to control the reboiler level and temperature while the top two squares are used to control the reflux drum level and manually manipulate the speed of feed and reflux pumps. Figure 11 shows programming of various control strategies employed for automatic control. 


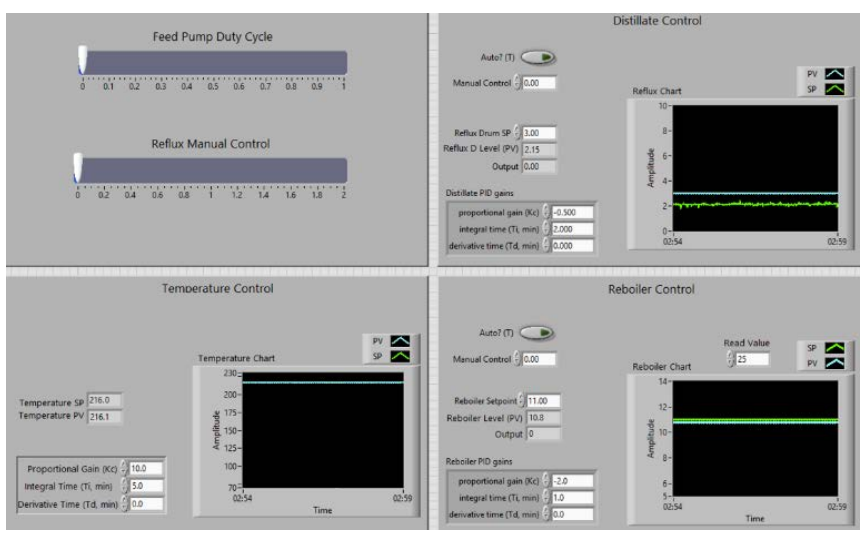

Figure 10. Front Panel
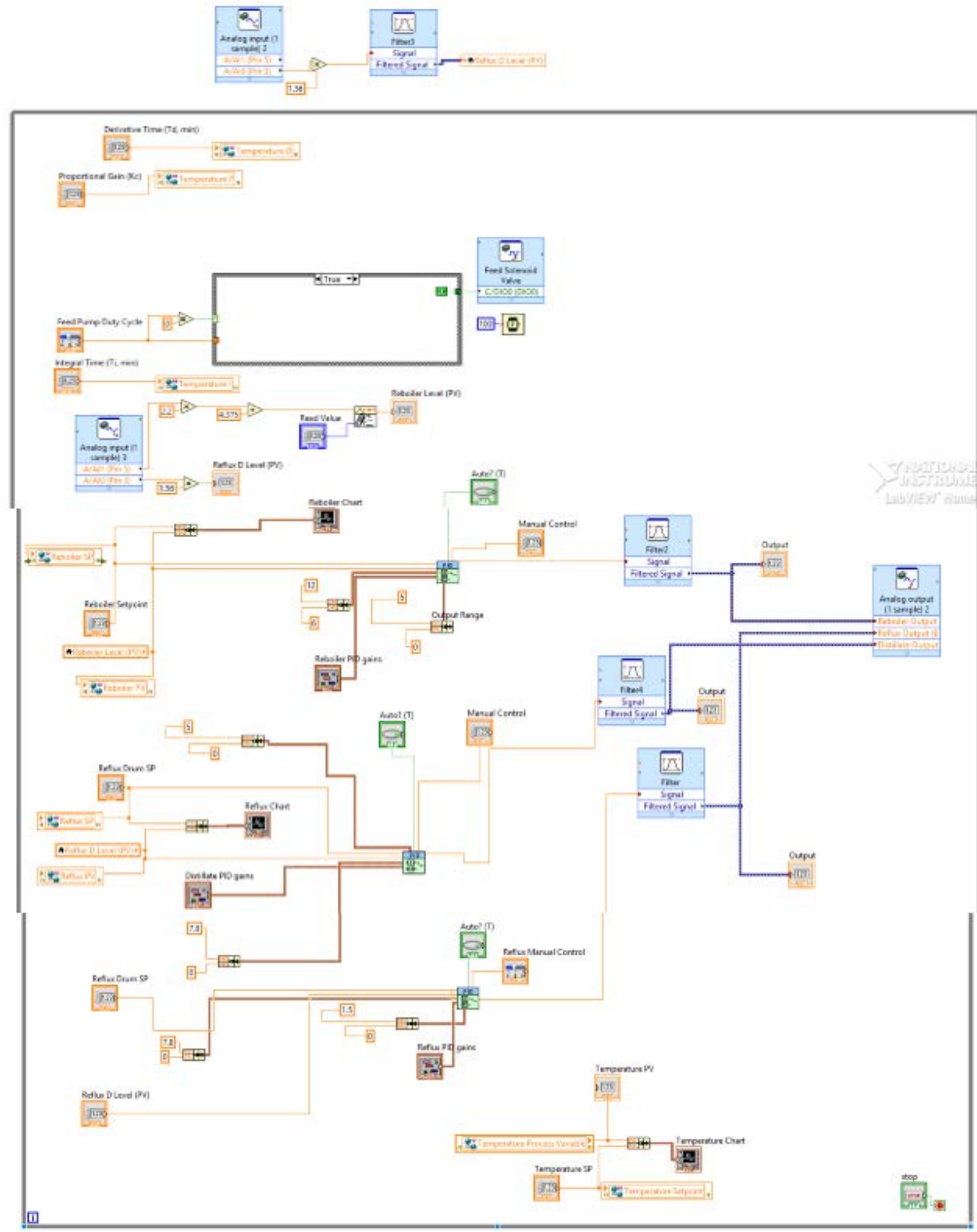

Fig. 11. LabVIEW Programming of Control Strategies 
The LabVIEW program consists of a single "while" loop that includes the reboiler temperature control, reflux drum and reboiler level controls, and manual speed operation for the feed and reflux pumps along with logic for a solenoid valve at the feed line.

The feed loop as seen in the top portion of Figure 11 is a simple pulse-width-modulation (PWM) block that takes its input from a digital input/output (DIO) on the NI myRIO. The output of the PWM is the Duty Cycle and LabVIEW limits the output from 0 to 1 . A slider is seen on the LabVIEW front panel as the manipulated variable for a constant flow of feed. Due to the design of the feed in this distillation column, a solenoid valve had to be added to prevent feed from free flowing into the column when the pump is not running. When the pump is at 0 duty cycle, the solenoid is de-energized and thus closed. When the slide on the duty cycle is greater than 0 , the NI myRIO sends a 5V output to a relay which completes a 12VDC circuit and energizes the solenoid causing it to open. The reflux drum and bottoms level control strategies are extremely similar. Both levels are controlled by LabVIEW's Advanced PID control block. The temperature control is done using a local controller by Platinum Omega ${ }^{3}$. The temperature set point, process variable, and PID gains are all local variables that are brought over to this LabVIEW diagram using a proprietary LabVIEW temperature controller demo by Platinum Omega.

\section{Instruments and Wiring}

Three power supplies with $12 \mathrm{VDC}$ output voltage and $10 \mathrm{amp}$ output current were used to power the pumps, H-Bridge, relay and converter. A fourth power supply with 12VDC output voltage and 5 amp output current was used to supply power to the distillate pump. A 24VDC output voltage and $1 \mathrm{amp}$ output current power supply was used to power the float transmitter in the boiler and radar transmitter in the reflux drum.

The distillate pump, reflux pump and reboiler pump are 12VDC high temperature water pumps with 0-5VDC speed manipulation range. They are connected to a power supply and to the myRIO analog output connections. The feed pump is a 12VDC pump without variable speed. In order to manipulate the pump, it was connected to an H-Bridge and to the myRIO using a PWM connection. An H-Bridge allows using the motor in either direction because it allows the current to flow in both directions. It is used adjust the motor speed by changing the duty cycle using PWM in LabVIEW. The feed solenoid uses a 12VDC power and a relay to set the open and closed limits on the valve. The float transmitter inside the boiler requires a current to voltage converter because the output signal is $4-20 \mathrm{~mA}$. The converter converts the $4-20 \mathrm{~mA}$ signal to $0-5 \mathrm{VDC}$ in order to connect to myRIO. Both the radar transmitter in the reflux drum and the float transmitter in the boiler required 24VDC power.

Figure 12 below shows the connections for the various instruments used for the distillation column. 


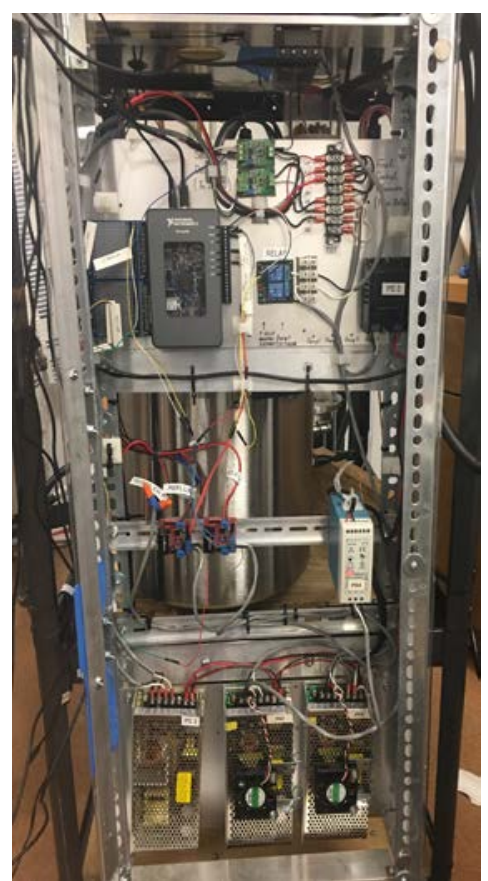

Fig. 12: Instrumentation and Wiring

\section{Results}

This section summarizes experimental results obtained while the distillation column was separating a mixture of ethanol and water. The composition of the feed to the column was approximately $4 \mathrm{wt} \%$ ethanol. The control loops were the liquid levels in the reflux drum and reboiler, and the temperature at the exit of the reboiler (vapor returned to column). As mentioned earlier, reflux drum level is controlled by manipulating the distillate pump voltage, reboiler level by manipulating the bottoms pump voltage and bottoms temperature by manipulating the heat input to the column. Proportional/integral (PI) controllers are used in these loops. The level loops were tuned manually while the temperature loop was tuned using the auto-tuning method included in the Platinum Omega temperature controller.

Figures 23 and 24 show level control. Both levels are measured in inches while the time is in minutes. Figure 25 show temperature control with the temperature measured in degrees Fahrenheit. All three figures show satisfactory column control.

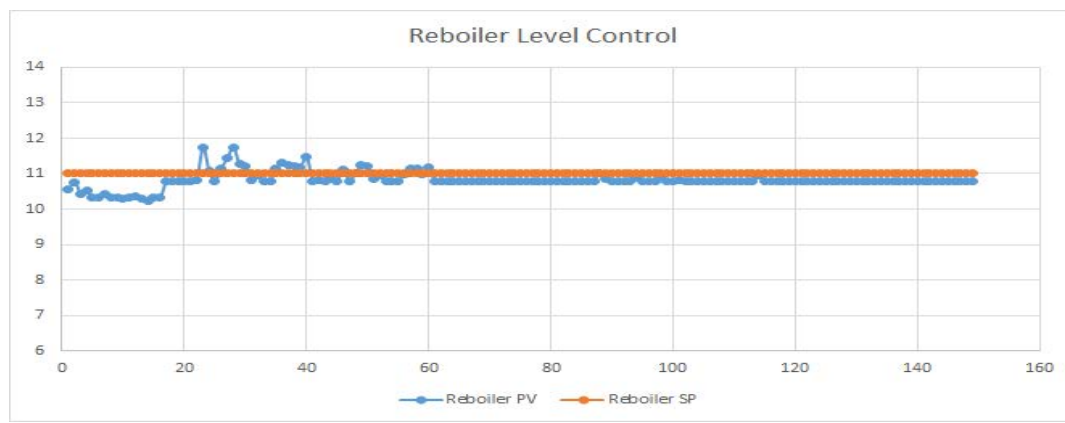

Fig. 23. Reboiler Level Control Chart 


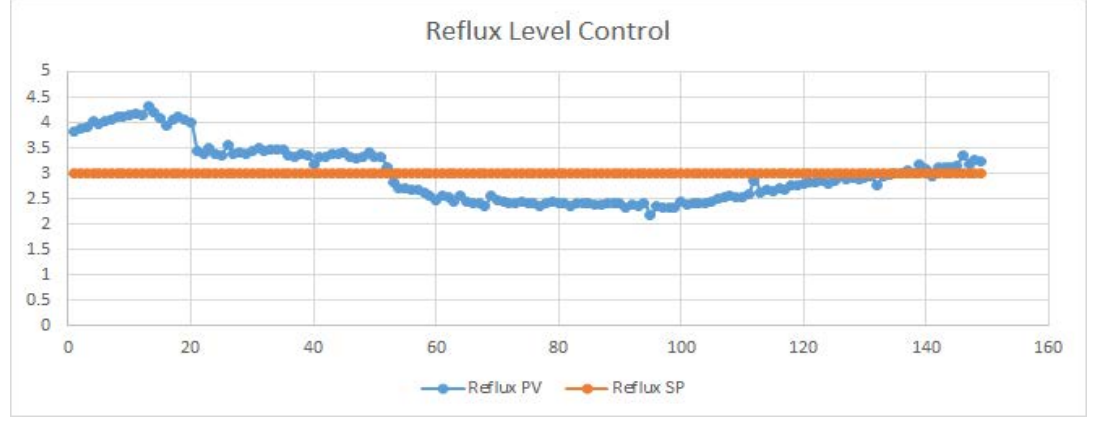

Fig. 24: Reflux Level Control Chart

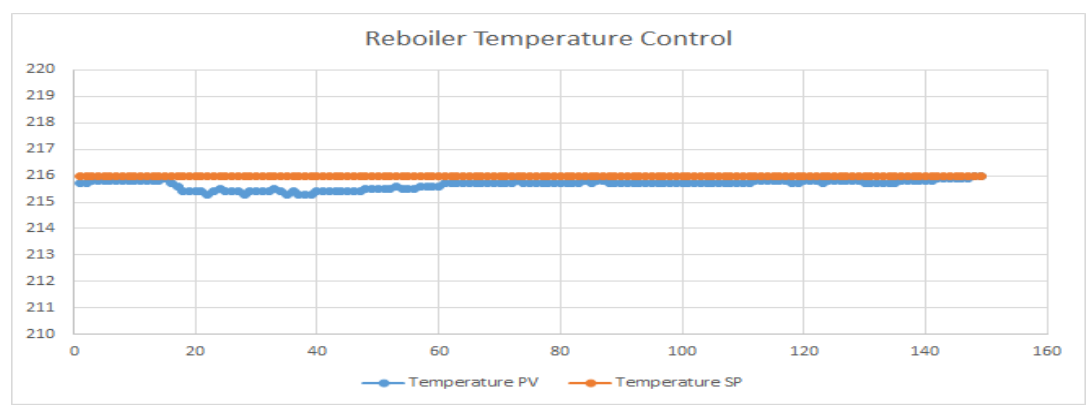

Fig. 25: Reboiler Temperature Control Chart

\section{Lessons Learned}

This section summarizes student comments and experiences by working on this capstone and design project.

- Balancing a full time job and the senior project was definitely tough. However, I could not have asked for a better team to embark on this challenging journey.

- From an organizational standpoint, the course structure ensured we stay on track with our schedule in order for every team to have a chance to be successful. The weekly status updates were an asset to the project as they allowed one on one time with the instructor where he provided any and all available resources he had to offer.

- The proposal, although we worked on a capstone project, enabled the instructor to approve the success criteria to be worked on for the semester as well as set expectations.

- The final presentation and report, as a combination, were a demonstration of all the hard work the three of us put in to achieve phenomenal results. All this was made possible with the help of each and every one of us. The input that each and every one of us had was first and foremost the reason behind our success.

- The most important part about teamwork, in my opinion, was communication; not just the ability to speak to one another, but also the ability to truly listen to one another. Our team met physically in the lab several times during this semester and brainstormed a lot of great ideas but we also communicated outside of the lab through a group chat which helped bring us close together as a team even with the challenges of life (work and family responsibilities).

- $\quad$ To the future students who are about to take on this task, I would recommend managing your time wisely while taking into consideration the time of other tasks in your life. This might sound easy but, as they say, it's a lot easier said than done. Make sure you also have the correct equipment from the beginning of your project. Be diligent in your research to ensure the compatibility of all the equipment you purchase. Finally, and this is for upcoming students who have just gotten into this program, make sure you pay attention in every class and take as much of the learnings you receive to 
heart because you will use every single piece of knowledge you have accrued along the years to be successful in your senior project.

- Working on our senior project was a profound experience for me. Learning to manage time availability between three students with very different time schedules was a perplexing problem to solve.

- $\quad$ The manor that the course was organized helped keep us on task by having us not just meet in person weekly but also making us give status updates to Dr. T.

- Having teams work on project proposal helped our team when it came to writing the final report. Just having the experience and understanding of what the standard for a technical report is helped meeting the set standard much easier.

- I think the biggest lesson I learned was how much technical knowledge I have accumulated over the years: from being able to use Excel to solve linear/nonlinear equations, to programming using LabVIEW, to using AspenPlus to design a distillation, to designing and tuning controllers.

- For future students embarking in the exciting, yet difficult task of a capstone project be sure to manage your time wisely. When the semester begins it feels like time is in abundance but soon your deadline approaches and then your stress levels go through the roof. Secondly, I would advise to take very specific notes when you come to the lab to work on the project. Trying to remember what issues the team faced two months ago is very difficult when facing a time crunch. Before the team leaves the lab use the mandatory lab book to write down everything the team struggled with and how the issues were eventually resolved.

- The senior project is a representation of what to expect as a professional in industry when working on a project. In industry, you work with several departments and professionals to get a project completed in a timely manner and within cost. These departments may include Instrumentation and Electrical Engineers, Process Engineers, Project Engineers, Mechanical Engineers, Design Technicians, and many more. In senior project, the small group completes every task crossing over into every field to complete the project. First, we have the duties of a project engineer. The class was structured so that we have weekly update meetings with our professor to discuss the group's progress similar to projects in industry. We also had a budget to manage and keep track of expenses. We used Aspen Plus to perform simulations to design the Distillation Column. We also used AutoCAD to draw the P\&ID of our system. We completed the wiring of all the instruments and did some pipe modifications. Students work hard to complete the project and the knowledge gained throughout the semester is so rewarding at the end when you do your final presentation and demonstration. Every mistake or problem encountered is knowledge and problem solving skills gained. It is very important to have a good team to work with. Everyone brought different ideas to table and we were able to execute them effectively to complete this project.

- Advice to other senior students: It is hard work and dedication that will get you through the project. It was possible for me as a mother of two and working a full-time job. Start off strong and finish strong. You should divide the work so that everyone is a leader in one area, however everyone should help finish the task by the projected date.

\section{Conclusions}

This paper presented results and student experiences from a capstone and design project on process automation. Students used sophisticated tools (the same ones used by industry) to design, construct and automate the operation of a distillation column. Results demonstrated the aptitude and skills of engineering technology students using sophisticated technologies to solve important technical problems while working in a team environment, communicating technical topics, and delivering results within budget and schedule constraints. In simple terms, the students' degree may be in engineering technology but their profession is engineering. 


\section{References}

1. AspenTech, “AspenPlus", www.aspentech.com

2. National Instruments, "myRIO”, www.ni.com

3. Platinum Omega, Temperature Controller, www.omega.com

4. Luyben, W.L., “Distillation Design and Control Using Aspen Simulation”, Wiley 2006.

\section{Appendix A: Distillation Column Design Using McCabe-Thiele Method}

In this appendix, details are provided on the distillation column using the McCabe-Thiele method. For more information, the interested reader is referred to a textbook by Luyben ${ }^{4}$. When using the McCabe-Thiele method, equimolar flows are assumed in the stripping and rectifying sections of the column. In the design of a binary distillation column, there are typically 5 degrees of freedom. If the feed (i.e. rate $\mathrm{F}(\mathrm{mol} / \mathrm{h})$, compositions $\left(\mathrm{z}_{\mathrm{i}}\right)$, temperature $\left(\mathrm{T}_{\mathrm{F}}\right)$, and pressure $\left(\mathrm{P}_{\mathrm{F}}\right)$ are known), column pressure and reflux ratio are specified, then for a desired separation (i.e. for specified distillate composition, $\mathrm{x}_{\mathrm{D}}$, and bottoms composition, $\mathrm{x}_{\mathrm{B}}$ ), the number of trays and feed tray location can be determined graphically by using the McCabe-Thiele method.

In the analysis that follows, the following parameters are defined:

- Feed rate $(\mathrm{F})$

- Feed molar composition (z, for light component)

- Feed thermal condition (q; 0 if vapor and 1 if liquid)

- Column operating pressure $(\mathrm{P})$

- Reflux flowrate (R)

- Distillate flowrate (D)

- Bottoms flowrate (B)

- Reflux Ratio (RR=R/D)

- Vapor rate in rectifying section $\left(\mathrm{V}_{\mathrm{R}}\right)$

- Vapor rate in stripping section (Vs)

- Liquid rate in rectifying section $\left(\mathrm{LR}_{\mathrm{R}}\right)$

- Liquid rate in stripping section (Ls)

- Distillate composition for light component $\left(\mathrm{x}_{\mathrm{D}}\right)$

- Bottoms composition for light component $\left(\mathrm{x}_{\mathrm{B}}\right)$

- Total number of trays $\left(\mathrm{N}_{\mathrm{T}}\right)$

- Feed tray $\left(\mathrm{N}_{\mathrm{F}}\right)$

Figure A.1 shows the different parameters on a schematic of a distillation column. 


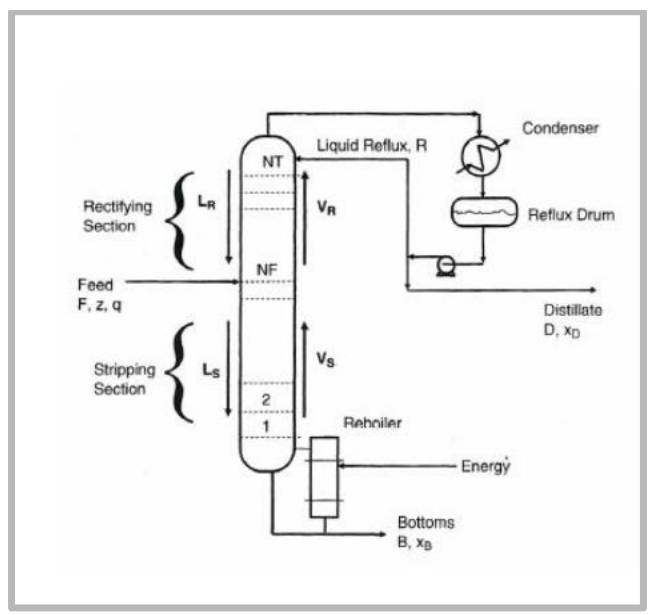

Fig.-3: Distillation Process Diagram ${ }^{4}$

Table A.1 shows the parameters and values used to design the column.

Table A.1: Distillation Column Design Data

\begin{tabular}{|c|c|c|}
\hline Feed Flow Rate, F & 1000 & moles/hr \\
\hline Feed Composition, z & 0.5 & moles of water/mole of mix \\
\hline Feed thermal condition, $q$ & 1 & (i.e. saturated liquid mixture) \\
\hline Relativity volatility, a & 35.52 & \\
\hline Distillate product composition, $\mathrm{X}_{\mathrm{D}}$ & 0.98 & moles of water/mole of mix \\
\hline Bottoms product composition, $x_{B}$ & 0.02 & moles of water/mole of mix \\
\hline Reflux Ratio, RR & 0.5 & \\
\hline
\end{tabular}

By solving material balances, the following relationships can be derived:

$$
\begin{gathered}
D=F \cdot \frac{z-x_{B}}{x_{D}-x_{B}} \\
R=R R \cdot D \\
V_{R}=R+D \\
\text { Slope of } R O L=\frac{L_{R}}{V_{R}}=\frac{R}{R+D}=\frac{R R}{1+R R} \\
L_{S}=q \cdot F+L_{R} \\
V_{S}=L_{S}-B
\end{gathered}
$$


The relative volatility, $\alpha$, of water with respect to propylene glycol is 32.52 at $66 \mathrm{C}$.

An excel spreadsheet is used to analyze the separation of water and propylene glycol by calculating the parameters in the McCabe-Thiele method and then plotting the data. Table A.2 shows results for the column design using the McCabe-Thiele method.

Table A.2: McCabe-Thiele Results

\begin{tabular}{|lll|}
\hline Distillate flow, $\mathrm{D}=$ & 510.6383 & $\mathrm{moles} / \mathrm{h}$ \\
Bottoms flow, $\mathrm{B}=$ & 489.3617 & $\mathrm{moles} / \mathrm{h}$ \\
Reflux Flow $\mathrm{R}=$ & 255.3191 & $\mathrm{moles} / \mathrm{h}$ \\
Vapor rate in rectifying section, VR= & 765.9574 & $\mathrm{moles} / \mathrm{h}$ \\
Vapor rate in stripping section, Vs= & 765.9574 & $\mathrm{moles} / \mathrm{h}$ \\
Liquid rate in rectifying section $\mathrm{LR}=$ & 255.3191 & $\mathrm{moles} / \mathrm{h}$ \\
Liquid rate in stripping section, $\mathrm{Ls}=$ & 1255.319 & $\mathrm{moles} / \mathrm{h}$ \\
Slope of rectifying operating line, ROL $=$ & 0.333 & \\
Slope of stripping operating line, SOL $=$ & 1.639 & \\
\end{tabular}

Using a $\boldsymbol{x} y$ vapor-liquid-equilibrium (VLE) diagram, the stripping and rectifying operating lines can be drawn as shown in Figure A.2. By following the McCabe-Thiele method, the number of required trays, NT, is shown to be 3 and the location of feed tray is 2 (from the column bottom).

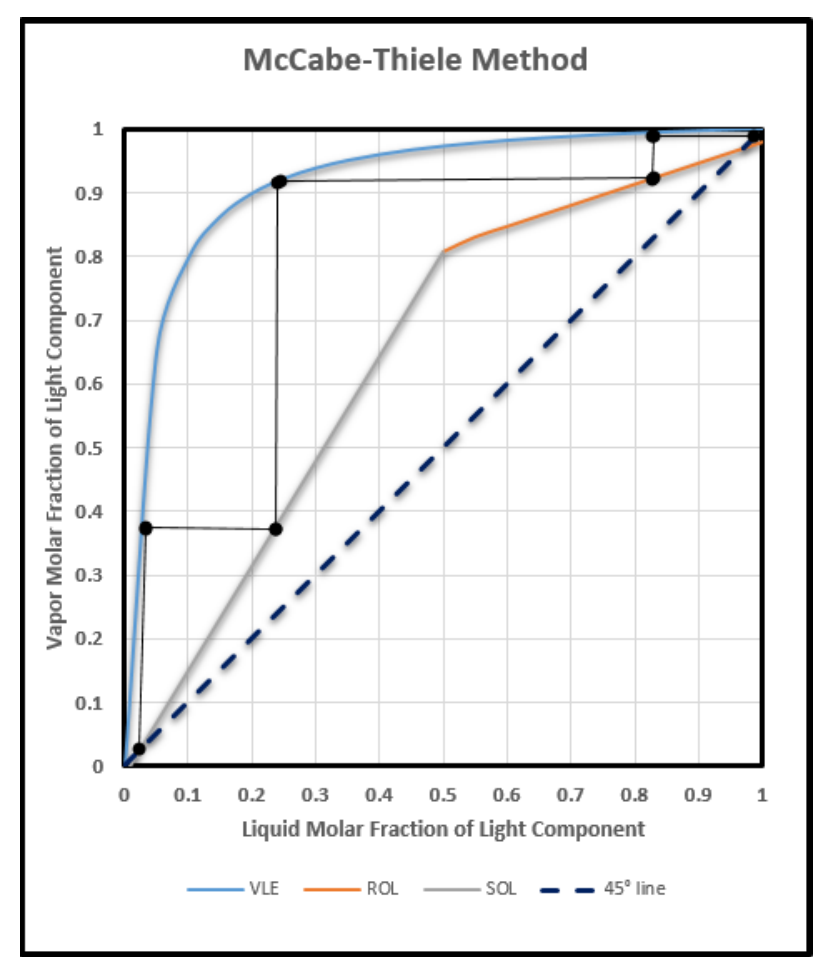

Figure A.2: McCabe-Thiele Method 


\section{Appendix B. Materials for Column Construction}

This appendix presents materials that were required to build the distillation column.

Table B.1: Major Equipment used to Construct the Column

\begin{tabular}{|c|c|}
\hline Component & Dimensions/Specifications \\
\hline Distillation Column Trays and Shell & $\begin{array}{l}\text { Overall Dimension: } \\
\text { - Height: } 4 \mathrm{ft} \\
\text { - Diameter = } 4 \text { ” } \\
\text { - } 7 \text { Trays }\end{array}$ \\
\hline Condenser -Heat Exchanger & $\begin{array}{l}\text { A } 1 / 2 \text { " spiral copper tube used to condense the } \\
\text { vapor coming from the top of the column into } \\
\text { liquid by having a hose connected to the tank } \\
\text { that then fills the tank with cool water and } \\
\text { another hose attached to the tank as the cold } \\
\text { water outlet. }\end{array}$ \\
\hline $\begin{array}{l}\text { Temperature Controller - PLATINUM } \\
\text { Series Temperature }\end{array}$ & $\begin{array}{l}\text { Control Modes } \\
\text { Action: Reverse (heat), direct (cool), or heat/cool } \\
\text { Auto-Tune: Operator initiated from front panel } \\
\text { Adaptive Tune: User selectable; fuzzy logic } \\
\text { continuous PID tuning optimization } \\
\text { Control Modes: ON/OFF or the following } \\
\text { time/amplitude proportional control modes; } \\
\text { selectable manual or auto PID, proportional, } \\
\text { proportional with integral, proportional with } \\
\text { derivative } \\
\text { Cycle Time: } 0.1 \text { to } 199 \text { seconds } \\
\text { Ramp and Soak: Up to } 99 \text { saved ramp and soak } \\
\text { programs, up to } 8 \text { ramp and } 8 \text { soak segments with } \\
\text { individually selectable events per program } \\
\text { Ramp and Soak Segment Times: } 00.00 \text { to } 99.59 \\
\text { (HH:MM) or } 00.00 \text { to } 99.59 \text { (MM:SS) } \\
\text { Source: } \\
\text { https://www.omega.com/manuals/manualpdf/M } \\
\text { 5451.pdf }\end{array}$ \\
\hline
\end{tabular}




\begin{tabular}{|c|c|}
\hline $\begin{array}{l}\text { Reflux Drum } \\
\text { Manufacturer: MILLIPORE }\end{array}$ & $\begin{array}{l}\text { - Capacity: } 2 \text { gallon } \\
\text { - Height: } 12 ” \\
\text { - Diameter: 7” } \\
\text { Source: } \text { http://www.emdmillipore.com/US/en }\end{array}$ \\
\hline Reboiler & $\begin{array}{l}\text { - The 240V BoilCoil }{ }^{\mathrm{TM}} \text { includes a "plug and play" } \\
12 \mathrm{ft} \text {. factory wired cable with a molded twist- } \\
\text { lock L6-30P plug on one end, and our custom } \\
\text { removable plug on the other end } \\
\text { - Less than Ultra low watt density means NO } \\
\text { chance of scorching when used as directed } \\
\text { - Features a professional and reliable connection } \\
\text { and sealing system engineered specifically for } \\
\text { homebrew kettles } \\
\text { Source: } \\
\text { http://www.blichmannengineering.com/products/boil } \\
\text { coil }\end{array}$ \\
\hline $\begin{array}{l}\text { (2) Solar DC Circulation Pump(s) } \\
\text { Manufacturer: Lightobject } \\
\text { Item \# : EWP-D50C124030L }\end{array}$ & 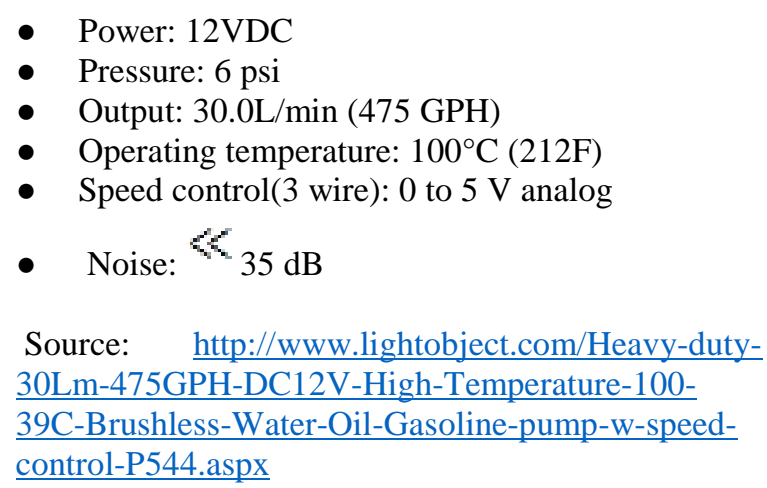 \\
\hline sis & $\begin{array}{l}\text { - Up to } 40 \text { lines of digital } \mathrm{I} / \mathrm{O}, 10 \text { analog input } \\
\text { channels, and } 6 \text { analog output channels for } \\
\text { connectivity to sensors and actuators } \\
\text { - Reusable from class to class and project to } \\
\text { project } \\
\text { Onboard WiFi and USB port for connectivity to } \\
\text { USB devices } \\
\text { Source: http://www.ni.com/pdf/manuals/376047c.pdf }\end{array}$ \\
\hline
\end{tabular}




\begin{tabular}{|c|c|}
\hline $\begin{array}{l}\text { Temperature sensor } \\
\text { Manufacturer: Honeywell } \\
\text { Item no. HEL-705-U-0-12-00 }\end{array}$ & $\begin{array}{l}\text { - Temperature Sensing Range }-70{ }^{\circ} \mathrm{C} \text { to } 260^{\circ} \mathrm{C}[- \\
\left.94{ }^{\circ} \mathrm{F} \text { to } 500^{\circ} \mathrm{F}\right] \\
\text { - } \quad \text { Linearity }\left(\% \text { of Full Scale) } \pm 0.1 \% \text { typ. }-40^{\circ} \mathrm{C} \text { to }\right. \\
125^{\circ} \mathrm{C}\left[-40^{\circ} \mathrm{F} \text { to } 257^{\circ} \mathrm{F}\right] ; \pm 2.0 \% \text { max. }-75^{\circ} \mathrm{C} \text { to } \\
540^{\circ} \mathrm{C}\left[-167^{\circ} \mathrm{F} \text { to } 1004^{\circ} \mathrm{F}\right] \\
\text { - } \quad \text { Stability: }>0,25^{\circ} \mathrm{C} \text { per year; } 0,05^{\circ} \mathrm{C} \text { per five } \\
\quad \text { years in occupied environment } \\
\text { - Supply Current } 1 \mathrm{~mA} \text { typ., } 2 \mathrm{~mA} \text { max. } \\
\text { Source: } \\
\text { http://sensing.honeywell.com/product- } \\
\text { page?pr_id=23053 }\end{array}$ \\
\hline $\begin{array}{l}\text { (1) Level sensor } \\
\text { Manufacturer: Madison }\end{array}$ & $\begin{array}{l}\text { - Select output type: } 4-20 \mathrm{~mA} \\
\text { - Length: } 16 \text { ” } \\
\text { - } \quad \text { Temperature Range: }-40^{\circ} \mathrm{C} \text { to } 105^{\circ} \mathrm{C} \\
\text { - Mounting: } 1-1 / 2 \text { ” fitting } \\
\text { - } 100 \text { psig Max Pressure } \\
\text { Source: } \\
\text { http://www.zoro.com/i/G2922936/?utm_source=goo } \\
\text { gle_shopping\&utm_medium=cpc\&utm_campaign=G } \\
\text { oogle_Shopping_Feed\&kpid=G2922936\&gclid=Cj0 } \\
\text { KEQiA- } \\
\text { uWjBRChu9ie05m5ipgBEiQAuHIuK2r3AqcYeOJU } \\
\text { JXtlCQ7I85ska1Ilc30a7cbPHehxbp8aArc08P8HAQ }\end{array}$ \\
\hline DX10 Echo Pod Radar Transmitter & $\begin{array}{l}\text { - } \quad \text { Range: } 49.2 ”(1.25 \mathrm{~m}) \\
\text { - } \quad \text { Accuracy: } 0.125 ”(3 \mathrm{~mm}) \\
\text { - } \quad \text { Process temp: } 20 \text { to } 140^{\circ} \mathrm{F}\left(-7 \text { to } 60^{\circ} \mathrm{C}\right) \\
\text { - } \quad 0-5 V \text { output } \\
\text { Source: } \\
\text { http://flowline.com/_data_sheet_and_manuals/curren } \\
\text { t/DL24_m.pdf }\end{array}$ \\
\hline Solid State Relay & $\begin{array}{l}\text { High Reliability, Vdc Input/Vac Output, Vac } \\
\text { Input/Vac Output } \\
\text { Source: Omega } \\
\text { http://www.omega.com/pptst/CNPT_SERIES.html }\end{array}$ \\
\hline Heat Sync & $\begin{array}{l}\text { Source: Omega } \\
\underline{\text { http://www.omega.com/pptst/CNPT_SERIES.html }}\end{array}$ \\
\hline
\end{tabular}




\begin{tabular}{|c|c|}
\hline Fast Blown Fuse and Fuse Box & $\begin{array}{l}\text { Source: Omega } \\
\text { http://www.omega.com/pptst/CNPT_SERIES.html }\end{array}$ \\
\hline Current to voltage converters & $\begin{array}{l}\text { 1. Work voltage: DC } 5-30 \mathrm{~V} \\
\text { 2. Operating temperature: }-20^{\circ} \mathrm{C} \sim 60^{\circ} \mathrm{C} \\
\text { 3. Maximum error: } 10 \mathrm{mv} \\
\text { 4. Accuracy: }+/-0.2 \% \\
\text { http://www.icstation.com/20ma-signal-current- } \\
\text { voltage-converter-module-p-7711.html }\end{array}$ \\
\hline
\end{tabular}

